\title{
Gating Charge Movement in Native Cells: Another Application of the Patch Clamp Technique
}

\author{
Oscar Vivas, Isabel Arenas and David E. García \\ Department of Physiology, School of Medicine, \\ Universidad Nacional Autónoma de México, UNAM. México, D.F.,
}

México

\section{Introduction}

Since the invention of the patch clamp technique by Neher and Sakmann (Hamill et al., 1981) macroscopic ionic currents can be recorded in neurons of a small diameter. Cortical neurons from mammals (Edwards et al., 1989) and even synaptic ends (Stuart and Sakmann, 1994) have been successfully patched in order to study many physiological phenomena which are sensitive to voltage changes. In addition, the activity of just one protein has been observed (Hamill and Sakmann, 1981; Sakmann et al., 1980). Unitary currents from a single voltage dependent channel can be recorded in a small patch of the plasma membrane. Both macroscopic and unitary currents allow understand the processes occurring once channels are opened.

However, there are various closed states before a channel opens and therefore, processes taking place during these closed states that to date are partially understood by either macroscopic or unitary currents. That is why gating charge movement occurring during transitional states of the channels should be studied. A case of a process taking place during closed states is the regulation of voltage dependent channels by G-proteins, which has begun to be studied by recording gating charge movement.

Voltage dependent calcium, potassium and even sodium channels are modulated by neurotransmitters (Hille, 1994; Ikeda and Dunlap, 1999). They exert its effect by activating G-protein coupled receptors (GPCRs). Neurotransmitter-induced activation of GPCRs can in turn activate several signaling pathways having pleiotropic effects on neurons (Hille, 1994; Hille et al., 1995) The molecule responsible for ion channel regulation has been identified to be $\beta_{\gamma}$ G-protein subunits $\left(G_{\beta_{\gamma}}\right)$ (Herlitze et. al., 1996; Ikeda, 1996). Binding of $G_{\beta_{\gamma}}$ to the channel induces characteristic changes. First, the current amplitude is reduced (Dunlap and Fischbach, 1981). Second, the voltage dependence of the channel is modified (Bean, 1989). Third, the activation kinetics of the current is slowed (Marchetti et. al., 1986). And fourth, $\mathrm{G}_{\beta_{\mathrm{y}}}$ unbinds from the channels by a strong depolarizing prepulse (Elmslie et. al., 1990; Grassi and Lux, 1989). However, it is still controversial whether $G_{\beta_{\gamma}}$ dimer diminishes the number of available channels by either changing the unitary conductance or modifying the structure of the channel through conformational changes, therefore altering its function. 
The aim of this chapter is to show that recording of the gating charge movement is a powerful tool to address ion channel regulation during transitional states. Firstly, we will overview briefly the fundamentals of the charge movement to point out the methodology required to successfully investigate gating charge movement. Then, we will discuss why cell lines or native cells can be chosen for recording gating charge movement. Following, the procedure to separate charge movement into components has to be carried out in the case of native cells. Finally, an application of studying charge movement to understand ion channel regulation should be addressed.

\section{Fundamentals of charge movement recording}

Many physiological functions are regulated by changes in membrane voltage through regulation of different proteins. Several proteins involved in membrane transport mechanisms (including ion channels, transporters and pumps) and G-protein coupled receptors are voltage dependent (Ben-Chaim et al., 2006; Hodgkin and Huxley, 1952). The molecular events that link changes in membrane voltage and the structural changes of these proteins, and thus to the regulation of physiological functions, seem to began with the displacement or reorientation of some amino acids capable of sensing the membrane voltage. This voltage sensor is the machinery required to transduce membrane potential to responses such as action potential conduction, neurotransmitter release, muscle contraction, secretion from endocrine cells and agonist binding sensitivity (Almers, 1978). Therefore, facilitating or hampering the displacement of the voltage sensor could be related to the regulation of these physiological functions.

During the study of the voltage dependence of action potential generation in nerve, Hodgkin and Huxley (1952) predicted, for the first time, the existence of molecules with charge or dipole movement capable of distribute or orientate in response to changes in the electric field. Today it is well accepted that gating charge movement correlates well with the opening and closing of sodium and potassium ion channels (Almers and Armstrong, 1980; Armstrong, 1975; Armstrong and Bezanilla, 1974; Bezanilla et al., 1982), which are responsible for the permeability changes occurring during an action potential. Positive charge amino acids, which constitute the voltage sensor of ion channels, are located in the fourth segment (S4) of each domain of the protein and S4 mutations alter gating charge movement and voltage dependence of the channels (Perozo et al., 1994; Stühmer et al., 1989). As a consequence of the movement of the voltage sensor a current is produced. This current is the so-called gating charge movement (Figure 1). Since the movement of these charged molecules is the first step in the transduction of voltage changes, gating charge movement precedes the opening and follows the closure of ion channels.

After Hodgkin and Huxley, there was an intense search of the current related to the opening and closing of the channels to corroborate the presence of polar molecules in the bilayer of cell membranes either in nerve or in muscle. This was firstly accomplished before the patch clamp technique invention in muscle (Schneider and Chandler, 1973) and in the squid giant axon (Armstrong and Bezanilla, 1973) by using an axial wire to clamp the voltage along the fiber. Gating charge movement is observed solely under favorable conditions since it is masked almost completely by capacitive and ionic currents, which are at least one order of magnitude bigger. For gating charge movement recording cells have to be bathed constantly with appropriated solutions designed to eliminate ionic components such as sodium, potassium and calcium currents. 


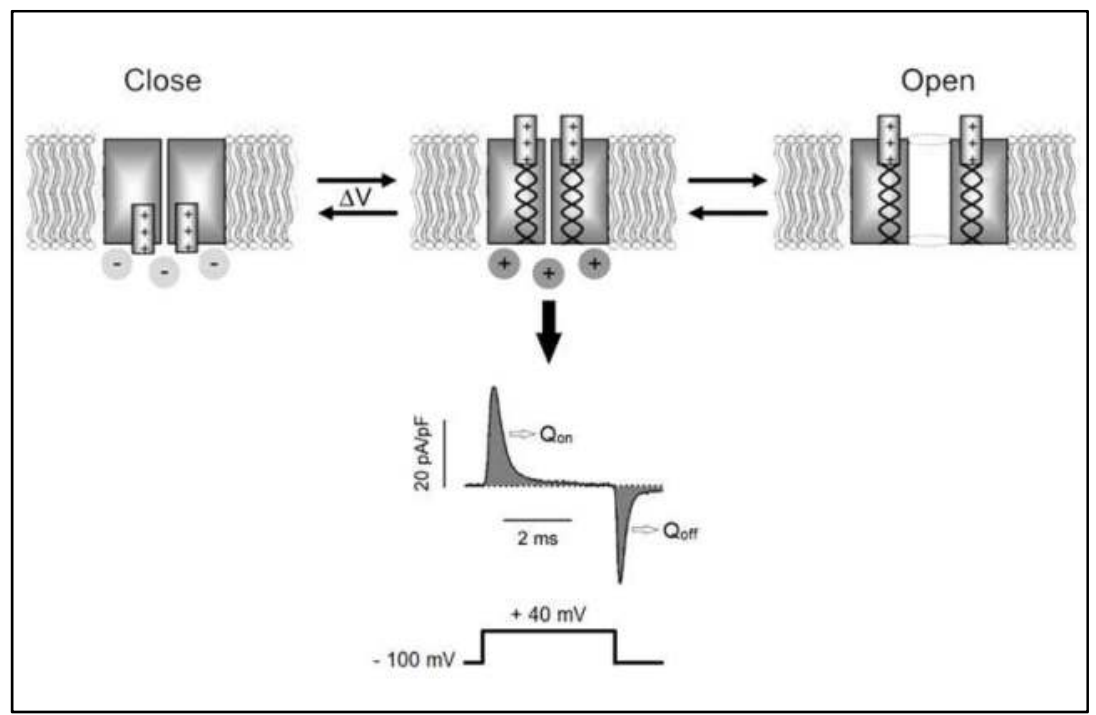

Fig. 1. Model that summarizes the origin of gating charge movement. According to the classical gating model (Horn, 2004; Starace and Bezanilla, 2004) a narrow portion of the S4 is in the gating pore where the membrane electrical field (dashed area surrounding voltage sensor) exerts its effect. Membrane depolarization $(\Delta V)$ exerts an electrostatic force on S4's positive charges that are within or near the membrane electrical field and thus can sense changes in the membrane voltage (the so-called gating charges). This causes S4 movements, resulting in a transfer of gating charges (coiled-coils into the electrical field) through the gating pore (gating charge transfer).

Ionic currents can be abolished by replacing permeant ions on both sides of the membrane by species that do not pass through the channels present in the membrane. Some typical replacements are tetraethylammonium (TEA), N-methylglucamine (NMG), some organic cations such as aspartate or glutamate and cesium. In addition to substitute permeant ions, it is common to use blockers such as tetrodotoxin (TTX), nifedipine and cadmium. One point to consider is the effect of some ions or blockers on the movement of the voltage sensor themselves since they would lead to a misinterpretation of the results. For example, we have designed an internal solution to study gating charge movement in neurons from superior cervical ganglion after several trials and experimental errors. It has been designed with cesium as the non permeant ion in the internal solution. Cesium based solution improves the sealing and extends the duration of the experiment by blocking ionic currents without altering the kinetics or voltage dependence of gating charge movement. Additionally TTX, cadmium and lanthanum are added to the external solution to block residual ionic currents (Hernandez-Ochoa et al., 2007).

When a depolarizing voltage pulse (test pulse) is given to a cell bathed with the solution stated above, the recording is comprised of a capacitive current, a small leak current and the gating charge movement. However the signal of the gating charge movement cannot be observed because it is under the portion of the slow linear capacitive component. This component does not change with time and voltage as it can be measured from the resting 
membrane potential. Taking advantage of the linear properties of the capacitive and leak currents, gating charge movement can be unmasked by means of a subtraction protocol applied before or after the test pulse. Figure 2A shows a protocol intended to subtract the linear components from the whole signal with 5 pulses of the fifth amplitude of the test pulse from a holding potential that does not elicit an ionic current $(\mathrm{P} /-5)$. Figure $2 \mathrm{~B}$ shows that voltage steps of opposite polarities, which are applied at the range of subtraction pulses, are totally cancelled by subtraction confirming the linear properties at these potentials. By contrast, gating charge movement behaves nonlinearly with voltage. There are a finite number of charges sensing voltage in the membrane, so that gating charge movement strongly depends on voltage and saturates (Figure 2C). Therefore the subtraction of a signal obtained at the range of voltage where only capacitive and leak currents are elicited let us obtain the recording of gating charge movement, whatever subtraction protocol is used (Figure 2D).

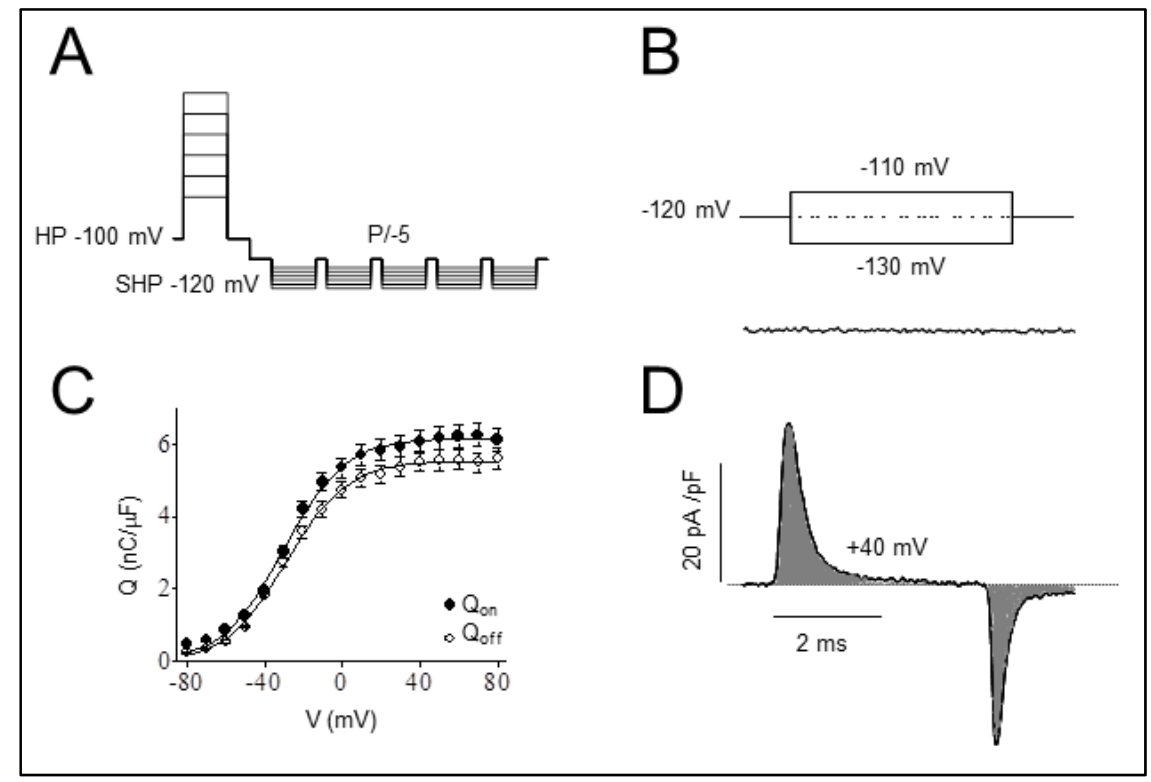

Fig. 2. General procedure to measure charge movement. A: a typical protocol for linearcomponents subtraction. B: absence of intramembrane charge movement at more negative potentials. C: Q-V relationship illustrating voltage dependence and saturation. D: typical recording of asymmetric current after linear-components subtraction. Shaded area under the curve represents charge movement. (Modified from Hernandez-Ochoa et al., 2007).

\section{Why native cells or cell lines?}

As stated before gating charge movement is at least one order of magnitude smaller than capacitive and ionic currents. In addition, the magnitude of gating charge movement depends on the number of voltage sensors moving in the cell membrane (Armstrong and Bezanilla, 1997; Noceti et al., 1996). Thus, the ideal system to study gating charge movement is a cell with a small capacitance but with a high density of channels. As an example of the 
latter, it has been successfully studied gating charge movement of only one type of channel in an expression system Xenopus oocytes (Bezanilla et al., 1991; Conti and Stühmer, 1989; Neely et al., 1994) or HEK cells (Starace et al., 1997).

Heterologous channel expression has led to significant advances in the molecular and functional understanding of gating charge movement. Channel expression in Xenopus oocytes has allowed to establish that gating charge movement is the consequence of protein conformational changes (Villalba-Galea et al., 2009) where each structural transition involves a quantum of charge (Conti and Stühmer, 1989), that the voltage sensor of the channels is the 4 transmembrane segment, S4 (Logothetis et al., 1992; Perozo et al., 1994), and that every transition from the closed to open state has a unique constant rate (Schoppa and Sigworth, 1998).

On the other hand, charge movement recording in native cells has the advantage of studying related phenomena in unaltered conditions. However, the study of charge movement in native cells is complicated by the presence of different types of channels, making difficult to know the contribution of each type of channel in the total charge movement recording (Chameau et al., 1995). In the case of the classical preparation of squid axons, the study of gating charge movement did not represent a problem due to the presence of only two population of channels at very high densities, sodium and potassium, and they could be readily separated by kinetic and temperature changes (Bezanilla, 1985; Gilly and Armstrong, 1980). In contrast, in mammalian ventricular cardiac cells were found that gating charge movement involving sodium and calcium channel populations, could not be separated (Bean and Rios, 1989).

\section{Separation of gating charge movement components in native cells}

In a previous report we show how to isolate and identify channels that are contributing to the total gating charge movement from a sympathetic neuron by two different approaches. The first approach analyzes gating charge movement kinetics. The hypothesis behind is that if sodium (Nav), calcium, (Cav) and potassium (A-type, $\mathrm{K}_{\mathrm{V}}$ ) channels with different constant times are contributing to the total gating charge movement, every component should be observed separated in time. This approach is essentially a kinetic separation of components of the gating charge movement. It has been used classically to establish the components of gating charge movement in skeletal muscle (Adrian and Peres, 1979; Francini et al., 2001; Huang, 1982; Huang, 1988).

An additional analysis compares the gating charge movement immobilization with voltagegated channel inactivation. Immobilization of gating charge movement can be associated with fast voltage-dependent inactivation of ion currents, such as $\mathrm{I}_{\mathrm{Na}}$ or $\mathrm{I}_{\mathrm{K} \text { (A) }}$ (Armstrong and Bezanilla, 1977; Bezanilla, 2000). Time- or voltage-dependent immobilization leads to differences in the charges moved between depolarization ( $\left.Q_{o n}\right)$ or repolarization ( $\left.Q_{\text {off }}\right)$. To test this possibility the voltage dependence of charge immobilization is compared to the voltage dependence of the steady-state inactivation for both ionic currents (Figure 3). Moreover, the parameters of a Boltzmann distribution fitted to gating charge movement immobilization and ionic current inactivation can help to determine which channel is mainly involved in the total gating charge movement. Following this approach we found that there is a component of gating charge movement that immobilizes with the same 
parameters of the $\mathrm{I}_{\mathrm{Na}}$ inactivation. Half-voltage was $-67.2 \mathrm{mV}$ and slope factor was $10.6 \mathrm{mV}$ for charge immobilization; half-voltage was $-67.4 \mathrm{mV}$ and slope factor was $6.7 \mathrm{mV}$ for $\mathrm{I}_{\mathrm{Na}}$ inactivation. This component is the two-thirds of the total charge movement. The other component, which does not immobilize probably arise from Cav2.2 calcium channels in SCG neurons. Bean and Rios (1989) also described two components of the total gating charge movement in rat and rabbit cardiac cells. With the same approach, they found that the $40 \%$ of the gating charge movement arises from sodium channels and hypothesized that the other $60 \%$ most probably arises from calcium channels.

The second approach uses non-stationary fluctuation analysis of currents. This analysis can be used to estimate the number of channels in the cell body of the neuron (Alvarez et al., 2002; Sigworth, 1980). Then, the maximal charge transferred during the gating charge movement $\left(\mathrm{Q}_{\max }\right)$ is compared to the charge transferred by one type of channel. To this end, ensembles of currents are generated by a serial of 80 to 200 identical and consecutive voltage pulses. The temporal course of the variance $\left(\sigma^{2}\right)$ and mean current of the ensemble is calculated. Since changes in $\sigma^{2}$ arise not only from stochastic gating of channels but also from thermal background noise, the temporal course of $\sigma^{2}$ at holding potential is subtracted. After correction of the $\sigma^{2}$, the relationship of mean current and $\sigma^{2}$ can be fitted to the following equation:

$$
\sigma^{2}=i(I)-(I)^{2} / N
$$

Where $I$ is the mean current, $N$ is the number of channels and $i$ is the unitary current. This theory is based on three general assumptions about voltage-gated channels: 1) Channels are composed of a homogeneous population 2) Channels population has a fixed number of independent gating channels and 3) Channels are assumed to exist in either a conducting or non conducting state.

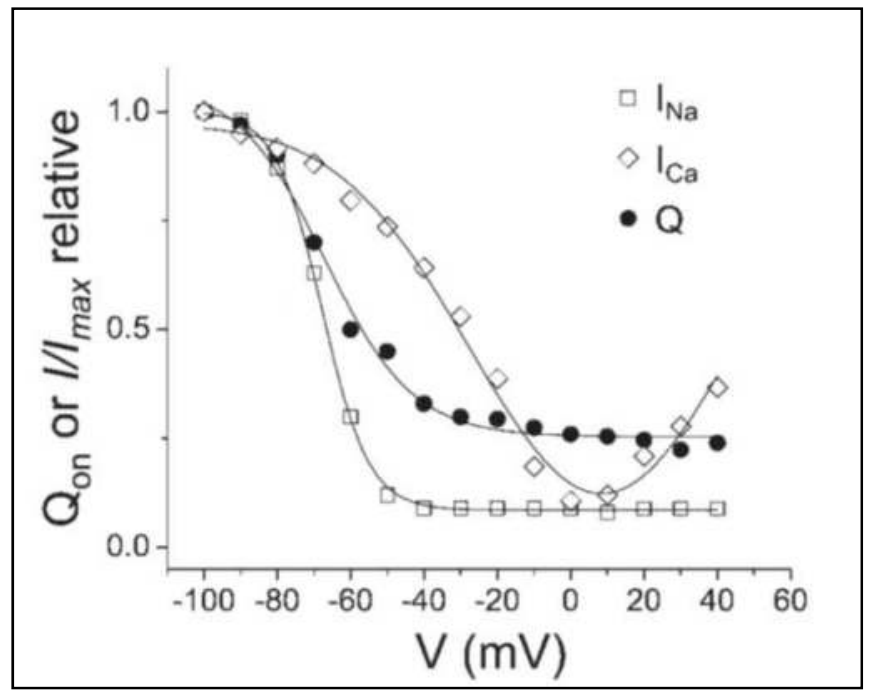

Fig. 3. Relationship between charge movement and two ionic-channel currents in a native cell (Modified from Hernandez-Ochoa et al., 2007). 
When the probability in the conducting state is maximal, the theory predicts a parabolic relation between $\sigma^{2}$ and the mean current that can be used to estimate the number of channels and the unitary current amplitude. We found that $3.8 \times 10^{4}$ calcium channels are in the cell body of one-day cultured SCG neuron of $40 \mathrm{pF}$, which it is equal to 9.5 channels $/ \mu \mathrm{m}^{2}$. Considering 12 elementary charges $\left(\mathrm{e}_{0}\right)$ equivalent gating charge per channel (Noceti et al., 1996) and that $Q_{\max }$ is equal to $6.2 \mathrm{nC} / \mathrm{cm}^{2}$ or, translated into elementary charges, $390 \mathrm{e}_{0}$ it would be 32 channels $/ \mu \mathrm{m}^{2}$ in rat sympathetic neurons. Thus, gating charge movement arising from calcium channels comprises approximately one-third of total gating charge movement. This value correlates well with our first approach in which two-third of total gating charge movement arises from $\mathrm{Na}_{V}$ channels while one-third from $\mathrm{Ca}_{V}$ channels.

\section{Ion channel regulation during closed states studied with gating charge movement recording}

Ion channels are regulated by a wide range of neurotransmitters through G-protein coupled receptors (Hille, 1994). Effector molecules of this neurotransmitter mediated regulation are $\beta \gamma$ subunits of heterotrimeric G-proteins (Herlitze et al., 1996; Ikeda, 1996). It has been proposed that G-protein regulation is carried out at the closed states transiting the channel toward its opening (Bean, 1989; Boland and Bean, 1993). Whole cell recording has been the most frequently used technique to study the effect of G-proteins on channels after they have opened, however channels are already regulated before ionic currents come into view. Thus, the effect of G-proteins during transitional states of the channels is still unclear. Since the transition between closed states involves the movement of the voltage sensor, regulation of ion channels at these states has been better understood through gating charge movement recording. The hypothesis that ion channels are regulated during closed states is strongly supported by the finding that the activation of G-proteins reduces gating charge movement (Hernandez-Ochoa et al., 2007). GTP $\gamma$ S dialysis, a non-hydrolysable activator of G-proteins, has three main effects on the voltage dependence of the total charge in SCG neurons: 1) a $34 \%$ decrease in $Q_{\max }, 2$ ) a $10 \mathrm{mV}$ shift of half-voltage toward positive voltage and 3) a $63 \%$ increase in the slope factor. These observations suggest that non-selective G-protein activation modifies both the voltage dependence and the number of available channels present in the cell body of SCG neurons. In addition, the activation of a specific signaling pathway by application of neurotransmitters such as noradrenaline or angiotensin II also reduces the gating charge movement.

Changes in gating charge movement recording under modulated conditions suggest that the voltage sensor of the channels is altered in such conditions. However, how voltage sensor activity can be modified by G-proteins? It has been proposed different mechanisms for modulating the properties of voltage sensors. All these studies have used gating charge movement recording to understand ion channel modulation.

Immobilization of gating charge movement is related with inactivation of channels, an intrinsic process of regulation of some voltage dependent ion channels (Armstrong and Bezanilla, 1977; Armstrong et al., 1973; Bezanilla and Armstrong, 1977; Bezanilla et al., 1991; Nonner, 1980). However, inactivation seems to be not the only process by which gating charge movement is immobilized. Recently it has been shown that modification of the lipid milieu induces immobilization of gating charge movement on potassium channels. The enzymatic removal of phosphate head groups of sphingomyelin diminishes gating charge 
movement by $90 \%$ without changes in the voltage dependence of the charge (Xu et al., 2008). In addition, toxins from several groups of animals alter ion channels (Sheets and Hanck, 1999; Sheets et al., 1999) by constraining conformational changes between transitional states (Catterall et al., 2007; Sokolov et al., 2008). This mechanism is called trapping. In molecular terms, it can be interpreted as withholding of the voltage sensor in resting or active position and thus the channel is modulated. Toxins can inhibit ion channel activation, deactivation or inactivation since they entrap the channel in the open, closed or inactivated conformation.

Another process that modulates ion channels, mainly potassium channels, is phosphorylation (Kaczmarek, 1988; Levitan, 1985). Throughout studying the effect of phosphorylation on gating charge movement of potassium channels it has been discovered that gating charge movement is reduced and that voltage dependence of the charge shifted toward positive potentials (Augustine and Bezanilla, 1990). The modulation of potassium channels is mediated by electrostatic interactions between voltage sensor and phosphate groups (Perozo and Bezanilla, 1990). In this case it can be interpreted as a screening of the potential profile.

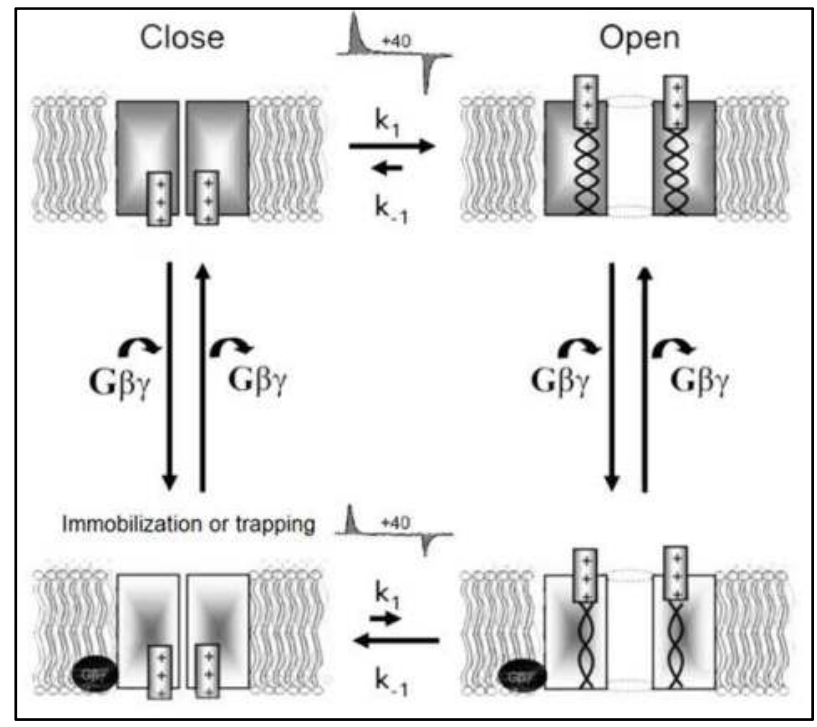

Fig. 4. Allosteric model to explain modulation of gating charge movement by G-proteins. This model postulates that the change in the number of gating charges (coiled-coils into the electrical field) due to G-protein $\beta \gamma$ subunits binding to the channel is by means of a redistribution of the local electric field that surrounds the voltage sensor (shown as a change in the color pattern) as a result of the allosteric modulation of the gating charge movement. (Modified from Rebolledo-Antunez et al., 2009).

The other molecules affecting gating charge movement are accessory subunits of the ion channels and ruthenium complexes. While accessory subunits of calcium channels improve the coupling between excitation and opening (Lacinova and Klugbauer, 2004), ruthenium complexes uncouples voltage sensor movement with the opening transition (Jara-Oseguera et al., 2011). All these possible changes: immobilization, trapping, screening, coupling or 
uncoupling, are examples of how ion channels can be modulated by means of changes in properties of the gating charge movement. Thus gating charge movement recording is a powerful tool to understand how ion channels are modulated.

Concerning G-protein modulation of ion channels is still unclear which mechanism could explain the inhibition of gating charge movement by neurotransmitters in SCG neurons. Inhibition of gating charge movement is commonly accompanied by a shift and an increase of the slope factor of the voltage dependence of the charge. In addition we have observed that during ion channel modulation, the effective charge is also reduced (RebolledoAntunez et al., 2009). Reductions in the effective charge, which is transferred during activation of the channel with a potential change (Figure 4), support the idea that G-proteins exert an allosteric modulation (Herlitze et al., 2001; Monod et al., 1965) of the gating charge movement, condition in which voltage sensors respond differentially to changes in the membrane potential.

\section{Conclusions}

This chapter offers an updated overview on the origin of the gating charge movement and points out the powerful application of this tool in understanding mechanistic processes underlying ion channel regulation. Furthermore, it illustrates a remarkable example using a model of ion channel regulation by G-proteins.

\section{Acknowledgment}

Supported by UNAM-DGAPA-PAPIT IN200710 grant, and a grant from The Alexander von Humboldt Stiftung, Germany to DEG.

\section{References}

Adrian, RH., \& Peres, A. (1979). Charge movement and membrane capacity in frog muscle. J Physiol. 289:83-97.

Almers, W. (1978). Gating currents and charge movements in excitable membranes. Rev Physiol Biochem Pharmacol. 82:96-190.

Almers, W., \& Armstrong, CM. (1980). Survival of K+ permeability and gating currents in squid axons perfused with K+-free media. J Gen Physiol. 75:61-78.

Alvarez, O., Gonzalez, C., and Latorre, R. (2002). Counting channels: a tutorial guide on ion channel fluctuation analysis. Adv Physiol Educ. 26:327-341.

Armstrong, CM. (1975). Currents associated with the ionic gating structures in nerve membrane. Ann N Y Acad Sci. 30:264:265-77.

Armstrong, CM., \& Bezanilla, F. (1973). Currents related to movement of the gating particles of the sodium channels. Nature. 242:459-61.

Armstrong, CM., \& Bezanilla, F. (1974). Charge movement associated with the opening and closing of the activation gates of the Na channels. J Gen Physiol. 63:533-52.

Armstrong, CM., \& Bezanilla, F. (1977). Inactivation of the sodium channel. II. Gating current experiments. J Gen Physiol. 70:567-590.

Armstrong, CM., Bezanilla, F., \& Rojas, E. (1973). Destruction of sodium conductance inactivation in squid axons perfused with pronase. J Gen Physiol. 62:375-391. 
Augustine, CK., \& Bezanilla, F. (1990). Phosphorylation modulates potassium conductance and gating current of perfused giant axons of squid. J Gen Physiol. 95:245-271.

Bean, BP. (1989). Neurotransmitter inhibition of neuronal calcium currents by changes in channel voltage dependence. Nature. 340:153-156.

Bean, BP., \& Rios, E. (1989). Nonlinear charge movement in mammalian cardiac ventricular cells. Components from $\mathrm{Na}$ and Ca channel gating. J Gen Physiol. 94:65-93

Ben-Chaim, Y., Chanda, B., Dascal, N., Bezanilla, F., Parnas, I., \& Parnas, H. (2006). Movement of 'gating charge' is coupled to ligand binding in a G-protein-coupled receptor. Nature. 444:106-9.

Bezanilla, F., White, MM., \& Taylor, RE. (1982). Gating currents associated with potassium channel activation. Nature. 296:657-9.

Bezanilla, F. (1985). Gating of sodium and potassium channels. J Membr Biol. 88:97-111.

Bezanilla, F. (2000). The voltage sensor in voltage-dependent ion channels. Physiol Rev. 80:555-592.

Bezanilla, F., \& Armstrong, CM. (1977). Inactivation of the sodium channel. I. Sodium current experiments. J Gen Physiol. 70:549-566.

Bezanilla, F., Perozo, E., Papazian, DM., \& Stefani, E. (1991). Molecular basis of gating charge immobilization in Shaker potassium channels. Science. 254:679-683.

Boland, LM., \& Bean, BP. (1993). Modulation of N-type calcium channels in bullfrog sympathetic neurons by luteinizing hormone-releasing hormone: kinetics and voltage dependence. J Neurosci. 13:516-533.

Catterall, WA., Cestele, S., Yarov-Yarovoy, V., Yu, FH., Konoki, K., \& Scheuer, T. (2007). Voltage-gated ion channels and gating modifier toxins. Toxicon. 49:124-141.

Chameau, P., Bournaud, R., \& Shimahara, T. (1995). Asymmetric intramembrane charge movement in mouse hippocampal pyramidal cells. Neurosci Lett. 201:159-162.

Conti, F., \& Stühmer, W. (1989). Quantal charge redistributions accompanying the structural transitions of sodium channels. Eur Biophys J. 17:53-9.

Dunlap, K., \& Fischbach, GD. (1981). Neurotransmitters decrease the calcium conductance activated by depolarization of embryonic chick sensory neurones. J Physiol. 317:519-35.

Edwards, FA., Konnerth, A., Sakmann, B., \&Takahashi, T. (1989). A thin slice preparation for patch clamp recordings from neurones of the mammalian central nervous system. Pflugers Arch. 414:600-612.

Elmslie, KS., Zhou, W., \& Jones, SW. (1990). LHRH and GTP-gamma-S modify calcium current activation in bullfrog sympathetic neurons. Neuron. 5:75-80.

Francini, F., Bencini, C., Piperio, C., \& Squecco, R. (2001). Separation of charge movement components in mammalian skeletal muscle fibres. J Physiol. 537:45-56.

Gilly, WF., \& Armstrong, CM. (1980). Gating current and potassium channels in the giant axon of the squid. Biophys J. 29:485-492.

Grassi, F., \& Lux, HD. (1989). Voltage-dependent GABA-induced modulation of calcium currents in chick sensory neurons. Neurosci Lett. 105:113-9.

Hamill, OP., Marty, A., Neher, E., Sakmann, B., \& Sigworth, FJ. (1981). Improved patchclamp techniques for high-resolution current recording from cells and cell-free membrane patches. Pflugers Arch. 391:85-100.

Hamill, OP., \& Sakmann, B. (1981). Multiple conductance states of single acetylcholine receptor channels in embryonic muscle cells. Nature. 294:462-464. 
Herlitze, S., Garcia, DE., Mackie, K., Hille, B., Scheuer, T., \& Catterall, WA. (1996). Modulation of Ca2+ channels by G-protein beta gamma subunits. Nature. 380:258-262.

Herlitze, S., Zhong, H., Scheuer, T., \& Catterall, WA. (2001). Allosteric modulation of Ca2+ channels by $G$ proteins, voltage-dependent facilitation, protein kinase $C$, and Ca(v)beta subunits. Proc Natl Acad Sci U S A. 98:4699-704.

Hernandez-Ochoa, EO., Garcia-Ferreiro, RE., \& Garcia, DE. (2007). G protein activation inhibits gating charge movement in rat sympathetic neurons. Am J Physiol Cell Physiol. 292:C2226-2238.

Hille, B. (1994). Modulation of ion-channel function by G-protein-coupled receptors. Trends Neurosci. 17:531-536.

Hille, B., Beech, DJ., Bernheim, L., Mathie, A., Shapiro, MS., \& Wollmuth, LP. (1995). Multiple G-protein-coupled pathways inhibit N-type Ca channels of neurons. Life Sci. 56:989-92.

Hodgkin, AL., \& Huxley, AF. (1952). A quantitative description of membrane current and its application to conduction and excitation in nerve. J. Physiol. 117:500-544.

Horn, R. (2004). How S4 segments move charge. Let me count the ways. J Gen Physiol. 123:1-4.

Huang, CL. (1982). Pharmacological separation of charge movement components in frog skeletal muscle. J Physiol. 324:375-387.

Huang, CL. (1988). Intramembrane charge movements in skeletal muscle. Physiol Rev. 68:1197-1147.

Ikeda, SR. (1996). Voltage-dependent modulation of N-type calcium channels by G-protein beta gamma subunits. Nature. 380:255-258.

Ikeda, SR., \& Dunlap, K. (1999). Voltage-dependent modulation of N-type calcium channels: role of G protein subunits. Adv Second Messenger Phosphoprotein Res. 33:131-51.

Jara-Oseguera, A., Ishida, IG., Rangel-Yescas, GE., Espinosa-Jalapa, N., Perez-Guzman, JA., Elias-Vinas, D., Le Lagadec, R., Rosenbaum, T., \& Islas, LD. (2011). Uncoupling charge movement from channel opening in voltage-gated potassium channels by ruthenium complexes. J Biol Chem. 286:16414-16425.

Kaczmarek, LK. (1988). The regulation of neuronal calcium and potassium channels by protein phosphorylation. Adv Second Messenger Phosphoprotein Res. 22:113-138.

Lacinova, L., \& Klugbauer, N. (2004). Modulation of gating currents of the Ca(v)3.1 calcium channel by alpha 2 delta 2 and gamma 5 subunits. Arch Biochem Biophys. 425:207-213.

Levitan, IB. (1985). Phosphorylation of ion channels. J Membr Biol. 87:177-190.

Logothetis, DE., Movahedi, S., Satler, C., Lindpaintner, K., \& Nadal-Ginard, B. (1992). Incremental reductions of positive charge within the $\mathrm{S} 4$ region of a voltage-gated $\mathrm{K}+$ channel result in corresponding decreases in gating charge. Neuron. 8:531-40.

Marchetti, C., Carbone, E., \& Lux, HD. (1986). Effects of dopamine and noradrenaline on Ca channels of cultured sensory and sympathetic neurons of chick. Pflugers Arch. 406:104-11.

Monod, J., Wyman, J., Changeux, JP. (1965). On the nature of allosteric transitions: a plausible model. J Mol Biol. 12:88-118.

Neely, A., Olcese, R., Wei, X., Birnbaumer, L., \& Stefani, E. (1994). Ca(2+)-dependent inactivation of a cloned cardiac Ca2+ channel alpha 1 subunit (alpha 1C) expressed in Xenopus oocytes. Biophys J. 66:1895-903. 
Noceti, F., Baldelli, P., Wei, X., Qin, N., Toro, L., Birnbaumer, L., \& Stefani, E. (1996). Effective gating charges per channel in voltage-dependent $\mathrm{K}+$ and $\mathrm{Ca} 2+$ channels. $J$ Gen Physiol. 108:143-155.

Nonner, W. (1980). Relations between the inactivation of sodium channels and the immobilization of gating charge in frog myelinated nerve. J Physiol. 299:573-603.

Perozo, E., \& Bezanilla, F. (1990). Phosphorylation affects voltage gating of the delayed rectifier K+ channel by electrostatic interactions. Neuron. 5:685-690.

Perozo, E., Santacruz-Toloza, L., Stefani. E., Bezanilla, F., \& Papazian, DM. (1994). S4 mutations alter gating currents of Shaker K channels. Biophys J. 66:345-54.

Rebolledo-Antunez, S., Farias, JM., Arenas, I., \& Garcia, DE. (2009). Gating charges per channel of $\mathrm{Ca}(\mathrm{V}) 2.2$ channels are modified by $\mathrm{G}$ protein activation in rat sympathetic neurons. Arch Biochem Biophys. 486:51-57.

Sakmann, B., Patlak, J., \& Neher, E. (1980). Single acetylcholine-activated channels show burstkinetics in presence of desensitizing concentrations of agonist. Nature. 286:71-73.

Schneider, MF., \& Chandler, WK. (1973). Voltage dependent charge movement of skeletal muscle: a possible step in excitation-contraction coupling. Nature. 242:244-6.

Schoppa, NE., \& Sigworth, FJ. (1998). Activation of shaker potassium channels. I. Characterization of voltage-dependent transitions. J Gen Physiol. 111:271-94.

Sheets, MF., \& Hanck, DA. (1999). Gating of skeletal and cardiac muscle sodium channels in mammalian cells. J Physiol. 514 (Pt 2):425-436.

Sheets, MF., Kyle, JW., Kallen, RG., \& Hanck, DA. (1999). The Na channel voltage sensor associated with inactivation is localized to the external charged residues of domain IV, S4. Biophys J. 77:747-757.

Sigworth, FJ. (1980). The variance of sodium current fluctuations at the node of Ranvier. J Physiol. 307:97-129.

Sokolov, S., Kraus, RL., Scheuer, T., \& Catterall, WA. (2008). Inhibition of sodium channel gating by trapping the domain II voltage sensor with protoxin II. Mol Pharmacol. 73:1020-1028.

Starace, DM., \& Bezanilla, F. (2004). A proton pore in a potassium channel voltage sensor reveals a focused electric field. Nature. 427:548-53.

Starace, DM., Stefani, E., \& Bezanilla, F. (1997). Voltage-dependent proton transport by the voltage sensor of the Shaker K+ channel. Neuron. 19:1319-27.

Stuart, GJ., \& Sakmann, B. (1994). Active propagation of somatic action potentials into neocortical pyramidal cell dendrites. Nature. 367:69-72.

Stühmer, W., Conti, F., Suzuki, H., Wang, XD., Noda, M., Yahagi, N., Kubo, H., \& Numa, S. (1989).

Structural parts involved in activation and inactivation of the sodium channel. Nature. 339:597-603.

Villalba-Galea, CA., Sandtner, W., Dimitrov, D., Mutoh, H., Knöpfel, T., \& Bezanilla, F. (2009).Charge movement of a voltage-sensitive fluorescent protein. Biophys J. 96:L19-21.

Xu, Y., Ramu, Y., \& Lu, Z. (2008). Removal of phospho-head groups of membrane lipids immobilizes voltage sensors of K+ channels. Nature. 451:826-829. 


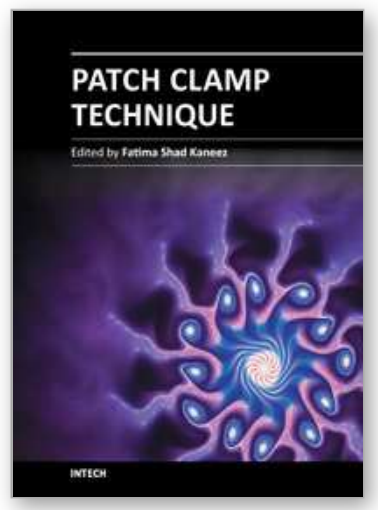

\author{
Patch Clamp Technique \\ Edited by Prof. Fatima Shad Kaneez
}

ISBN 978-953-51-0406-3

Hard cover, 356 pages

Publisher InTech

Published online 23, March, 2012

Published in print edition March, 2012

This book is a stimulating and interesting addition to the collected works on Patch clamp technique. Patch Clamping is an electrophysiological technique, which measures the electric current generated by a living cell, due to the movement of ions through the protein channels present in the cell membrane. The technique was developed by two German scientists, Erwin Neher and Bert Sakmann, who received the Nobel Prize in 1991 in Physiology for this innovative work. Patch clamp technique is used for measuring drug effect against a series of diseases and to find out the mechanism of diseases in animals and plants. It is also most useful in finding out the structure function activities of compounds and drugs, and most leading pharmaceutical companies used this technique for their drugs before bringing them for clinical trial. This book deals with the understanding of endogenous mechanisms of cells and their receptors as well as advantages of using this technique. It covers the basic principles and preparation types and also deals with the latest developments in the traditional patch clamp technique. Some chapters in this book take the technique to a next level of modulation and novel approach. This book will be of good value for students of physiology, neuroscience, cell biology and biophysics.

\title{
How to reference
}

In order to correctly reference this scholarly work, feel free to copy and paste the following:

Oscar Vivas, Isabel Arenas and David E. García (2012). Gating Charge Movement in Native Cells: Another Application of the Patch Clamp Technique, Patch Clamp Technique, Prof. Fatima Shad Kaneez (Ed.), ISBN: 978-953-51-0406-3, InTech, Available from: http://www.intechopen.com/books/patch-clamp-technique/gatingcharge-movement-in-native-cells-another-application-of-the-patch-clamp-technique-

\section{INTECH}

open science | open minds

\section{InTech Europe}

University Campus STeP Ri

Slavka Krautzeka 83/A

51000 Rijeka, Croatia

Phone: +385 (51) 770447

Fax: +385 (51) 686166

www.intechopen.com

\section{InTech China}

Unit 405, Office Block, Hotel Equatorial Shanghai

No.65, Yan An Road (West), Shanghai, 200040, China 中国上海市延安西路65号上海国际贵都大饭店办公楼 405 单元

Phone: +86-21-62489820

Fax: $+86-21-62489821$ 
(C) 2012 The Author(s). Licensee IntechOpen. This is an open access article distributed under the terms of the Creative Commons Attribution 3.0 License, which permits unrestricted use, distribution, and reproduction in any medium, provided the original work is properly cited. 